\title{
Goldman and Siegel on the epistemic aims of education
}

\section{ALESSIA MARABINI AND LUCA MORETTI}

\begin{abstract}
Philosophers have claimed that education aims at fostering disparate epistemic goals. In this paper we focus on an important segment of this debate involving conversation between Alvin Goldman and Harvey Siegel. Goldman claims that education is essentially aimed at producing true beliefs. Siegel contends that education is essentially aimed at fostering both true beliefs and, independently, critical thinking and rational belief. Although we find Siegel's position intuitively more plausible than Goldman's, we also find Siegel's defence of it wanting. We suggest novel argumentative strategies that draw on Siegel's own arguments but look to us more promising.
\end{abstract}

\section{INTRODUCTION}

At the dawn of Western philosophy, the debate on the ultimate epistemic aims of education played a central role in the dispute between Socrates and the sophists, and it informed Plato's major works, such as Republic and Laws. This longstanding and venerable debate is still on-going. Philosophers have recently claimed that education aims at fostering disparate epistemic goals — for instance: knowledge, true belief, justified belief, understanding, epistemic character, critical thinking, etc. (For an overview see Watson 2016 and Siegel and Eamonn 2018). In this paper we focus on an important segment of this debate involving conversation between Alvin Goldman and Harvey Siegel. Goldman (1999) maintains that education is essentially aimed at producing true belief. Siegel (2005) contends that education essentially aims at fostering true belief and independently critical thinking and rational belief. We analyse both positions by paying particular attention to Siegel's arguments. We find Siegel's view intuitively more plausible than Goldman's, but we also find his defence wanting. We suggest two additional arguments in support of Siegel's position. 
Siegel (2005) also aims to reject Goldman (1999)'s thesis that mere trust in the teacher's testimony often needs to supplant students' critical thinking. Siegel's arguments presuppose a form of reductionism about testimony that we fear most epistemologists would not accept. We suggest a new strategy of response to Goldman that isn't burdened with this type of reductionism about testimony.

Although this article defends the epistemic value of critical thinking and rational belief, let us clarify that we agree with Siegel $(1988,1997,2005$ and 2017) that there are many non-epistemic reasons (e.g., moral, practical, and psychological) for regarding critical thinking and rational belief as fundamental components of education. We don't examine these independent reasons here, but we don't underrate their importance.

The very notion of epistemic isn't free from problems. It is unclear, for instance, how and indeed whether epistemic and non-epistemic properties and values can be held apart. Some philosophers from both the continental camp (see for example Williams 2015) and the analytic camp (see for instance Fantl \& McGrath 2009) contend that these proprieties and values are inextricably entangled. This is another issue that may have important consequences in epistemology of education, but which cannot be addressed here. In this paper, we will be working within Goldman and Siegel's model, which presupposes that epistemic and non-epistemic properties and values are distinct.

This is the structure of the paper: in the next section we outline the dispute between Goldman and Siegel on the epistemic aims of education. After that, we analyse and criticize Siegel's arguments in support of his form of epistemic pluralism. Then, we outline two additional arguments in defence of it. In the penultimate section, we survey the dispute between Goldman and Siegel on the value of testimony in education and suggest a novel argumentative strategy on Siegel's behalf. The last section delivers our conclusions. 


\section{THE DISPUTE BETWEEN GOLDMAN AND SIEGEL}

In Knowledge in a Social World (1999), Goldman introduces veristic social epistemology (VSE), which investigates how individuals can acquire true beliefs ${ }^{1}$ from their interactions with other individuals through various social practices involving, for instance, ordinary testimony and mass

media communication. In doing so, VSE also investigates epistemic features of social institutions. It enquires whether institutions like legal, scientific and educational systems produce true beliefs and prevent false beliefs in those who use them. Goldman maintains that acquiring true belief and avoiding false belief is our 'dominant epistemic goal' (1999: 24). In short, he maintains that true belief is the ultimate or final epistemic goal (cf. 1999: 3 and 87). ${ }^{2}$ Furthermore, Goldman endorses a moderate multiculturalism but contrasts VSE with postmodern or veriphobic approaches to social epistemology that reject the existence of an objective, mind-independent truth while advocating constructivism, anti-representationalism, antirealism, pragmatism, metaphysical or epistemic relativism.

Goldman recognizes that education as a social institution may have various aims other than true belief. For instance, vocational education may aim at fostering, among other things, practical skills irreducible to true beliefs. Goldman nevertheless claims that the promotion of true belief in learners is 'education's most pervasive and characteristic goal' (1999: 349).

For Goldman, there are various effective pedagogical methods to produce true beliefs in learners, in addition to the traditional "stand and deliver".

Education pursues this mission in several ways: by organizing and transmitting pre-existing [true beliefs], by creating incentives and environments to encourage learning, and by shaping skills and techniques that facilitate autonomous learning and steer inquiry toward truth. (1999: 343)

Goldman also recognizes that education may have diverse epistemic goals - e.g., fostering epistemic responsibility, rational belief and critical thinking — but he contends that these aims are all mere (fallible) means or instruments to the ultimate epistemic goal of true belief. ${ }^{3}$ Goldman is 
thus a monist about the ultimate epistemic goal of education. He rejects the alternative monist view — defended by Siegel (1988) — that the final epistemic goal of education is fostering critical thinking.

Critical thinking is described by Siegel as the combination of the ability to reason well (i.e., to construct and evaluate the reasons that have been or can be offered in support or criticism of beliefs, judgments and actions) and the disposition to be guided by reasons so evaluated (i.e., to actually believe, judge and act in accordance with the results of rational evaluations) (cf. 1988: 4344 and 2003: 305). The notion of critical thinking is closely associated by Siegel with the one of autonomy (cf. 1988: 54). For a person provided with critical thinking is one capable of assessing for herself reasons in support or against beliefs, judgments and actions (cf. 2003: 307). Siegel locates his view within the tradition drawing from Kant, Sellars and McDowell that conceives of educating as cultivating reason.

Against Siegel (1988), Goldman claims:

I do not see critical thinking as an epistemic end in itself... Critical thinking... is a useful means to the fundamental end of true belief. (1999: 363)

His point is that critical thinking in students produces rational or justified beliefs, which are often true beliefs. Goldman (1992: 105-126) maintains that the justification of a belief coincides with or is a function of the reliability of the processes that cause the belief, where reliability is thought of as the property of producing more truths than falsities. This is the actual reason why, according to Goldman, critical thinking and justified belief are valuable from an epistemic point of view in education.

Goldman also stresses that the use of critical thinking in education cannot but have an important scope limitation: many claims made by teachers must be taken uncritically on trust by students — they must be accepted without any evidence or reason in their support. For teachers 
cannot always provide reasons for the reasons they give. Also because of this, critical thinking isn't as fundamental as Siegel thinks in education (cf. 1999: 363-364).

In his more recent paper 'Truth, thinking, testimony and trust' (2005), Siegel clarifies that, like Goldman, he endorses a moderate multiculturalism and opposes veriphobic/postmodern approaches that reject the existence of an objective, mind-independent truth. Siegel also acknowledges — correctly in our view — that in educational contexts the beliefs that students are normally supposed to entertain are assumed to be true. Hence, Siegel drops his former monistic view about the ultimate epistemic goal of education but argues — against Goldman — in defence of a pluralist view. Siegel characterizes his new position as follows:

On the view of 'the crucial epistemic aim' that I favor, education should strive to foster, not (just) true belief, but (also) the skills, abilities and dispositions constitutive of critical thinking, and the rational belief generated and sustained by it. (Siegel 2005: 347)

Rational belief, and the critical thinking on which it typically depends, are not then merely instrumentally valuable in light of their tie to true belief; rather, they are as fundamental, as epistemic aims of education, as is true belief. (Siegel 2005: 350)

For Siegel, rational belief and critical thinking are very intimately related, although rationality is the more general notion; critical thinking is, for him, the "educational cognate" of rationality (cf. 2005: 347n4). Beliefs reached via critical thinking are, for Siegel, rationally justified. On his pluralism, education ultimately aims at fostering true belief and critical thinking, which typically generates and sustains rational belief.

Unlike Goldman, Siegel doesn't identify the rationality or justification of a belief with the reliability of the process that has produced it. Siegel endorses (or sympathizes for) an evidentialist conception of justification, according to which the justification of a belief is a matter of, not reliability, but of whether the belief fits one's evidence. In particular, one's belief is justified with a strength proportional to the weight of the evidence for it that one possesses (cf. 2005: 354). Siegel 
also accepts 'the standard view among epistemologists... of the relationship between truth and rationality or justification - i.e., that the latter are fallible indicators of the former' (2005: 349).

\section{SIEGEL'S ARGUMENTS FOR EPISTEMIC PLURALISM IN EDUCATION}

Siegel observes that from the fact that VSE investigates how social practices and institutions promote true belief it doesn't follow that these social practices and institutions have the promotion of true belief as their own ultimate epistemic goal. Still less does it follow that they have the promotion of true belief as their sole final epistemic aim (cf. 2005: 349). What Siegel suggests is that Goldman would need to supply arguments in support of his epistemic monism about education — arguments that he doesn't actually provide.

Note that Goldman would still need arguments to support his epistemic monism about education even if his general epistemic monism (independent of education) turned out to be correct — so even if the ultimate epistemic goal simpliciter (or tout court) turned out to be just true belief. ${ }^{4}$ When we ask what the ultimate epistemic aims of education are, we ask (i) what epistemic aims or functions education has intrinsically, in virtue of its own nature, when education is conceived of as a social practice or institution, and (ii) which of these aims are final (i.e., which ones aren't mere means to or constituents of other aims that education has intrinsically). It isn't implausible to think that if acquiring true belief were the ultimate epistemic goal simpliciter, education should aim at making learners achieve this important goal. So, promoting true beliefs would be an ultimate epistemic goal of education. Even so, it wouldn't be obvious or self-evident, in this case, that promoting true beliefs should be the sole ultimate epistemic goal of education.

We now turn to Siegel's four arguments in support of his form of epistemic pluralism in education. (Although we have individuated four distinct cases, our framework might not be completely faithful to Siegel 2005, as some of his arguments tend to blend with others.) Here is the first argument: 
If fostering true belief were the sole ultimate epistemic goal of education, teachers would aim at inculcating true beliefs irrespective of the method. So 'many objectionable ways of achieving it - brainwashing, indoctrination, fabrication, deception, chemical manipulation, etc. — would be permissible. But they are not.' (2005: 349).

This argument aims at discrediting Goldman's epistemic monism in education. If it were cogent, it would support Siegel's form of pluralism indirectly. We don't find the argument convincing. For we doubt that the subjunctive-conditional in it is true. We suspect that if promoting true belief were the sole ultimate epistemic goal of education, most teachers would still have reasons for not using 'objectionable' methods like those mentioned by Siegel. Hence, these methods would not be permissible. For instance, teachers and curricula designers could still find practices like brainwashing and indoctrination abhorrent from an ethical point of view and quite independently of the functions of education. Also, teachers and curricula designers should rule out fabrication and deception simply because these methods would require them to induce false evidential beliefs in students. ${ }^{5}$ But this would conflict with the ultimate epistemic goal of education. Finally, in case of chemical manipulation, one might contend that methods like this are actually permissible chemical manipulation could for instance facilitate one's learning of large amounts of numerical data — but that they aren't in use because they aren't yet technologically available (cf. Buckland 2016: 106).

Siegel's second argument aims at directly supporting his form of epistemic pluralism:

(i) It is accepted that 'teaching must be carried out under appropriate restrictions of manner: as teachers, we aim to get students to believe curricular content that we ourselves take to be true, for reasons that we take to be good reasons for regarding that content as true; we aim further that our students' resulting true beliefs will be held on the basis of those reasons'. (2005: 349).

(ii) This is so because 'rational belief, and the critical thinking on which it typically depends, are not... merely instrumentally valuable in light of their tie to true belief; rather, they are as fundamental, as epistemic aims of education, as is true belief' (2005: 350). ${ }^{6}$ 
We don't find this case fully convincing because its premise (i) — though plausible in itself — could be argued not to be a reason sufficient to warrant belief in the conclusion (ii). (ii) is meant to gain credibility by providing the best explanation of (i). However, advocates of Goldman's epistemic monism might insist that an alternative, prima facie equally good explanation of (i) is this:

(ii*) This is so because teaching students truths together with reasons for believing them is a very effective way to inculcate true beliefs. ${ }^{7}$ Furthermore, in this way we can productively teach students true beliefs and, simultaneously, skills to acquire true beliefs - i.e., critical thinking.

Note that accepting (ii*), instead of (ii), doesn’t require rejecting Goldman's view that promoting true belief is the sole ultimate goal of education.

Siegel's third case defends epistemic pluralism by adducing as premises the descriptions of two thought experiments involving two students, Maria and Mario. Imagine Maria and Mario take the same exam and answer the same question by stating that $P$.

(a) [Suppose first that] Maria and Mario... both... truly believe that $P$. [However,] Maria's belief is rational in that it was generated and is sustained by her critical thinking, while Mario's is not - Mario's is a lucky true belief. It is uncontroversial [to any teacher] that... Maria's belief is more valuable epistemically than Mario's...

(b) The same valuation obtains in the case in which $P$ is false... Maria's and Mario's beliefs have the same truth value; again, [as teachers,] we judge Maria's superior to Mario's...

(c) [Therefore, in education,] rationality/justification has [epistemic] value independently of its instrumental tie to truth. (2005: 351 , our emphasis)

We find premises (a) and (b) fairly plausible. Siegel thinks that (a) and (b) give independent reasons to believe (c). This is Siegel's explanation:

[In case (a) and in case (b)] the only difference between otherwise identical beliefs is that one is rationally held, on the basis of the exercise of critical thinking, while the other is not — that is, [in each of these two] cases... everything is held constant (including truth value) except rational or justificatory status. If... one [belief] is epistemically more valuable than the other, we have a reason to think that the value of that which distinguishes between the two [beliefs] is not merely instrumental with respect to truth. (2005: 351) 
The last sentence in the quotation calls for explanation. This is what Siegel has presumably in mind. Consider (a). Maria's belief is epistemically valuable as well as Mario's because they are both true. Yet it is intuitive that Maria's belief has additional epistemic value because - unlike Mario's - it is justified via her critical thinking. Suppose, however, that true belief were the only ultimate epistemic aim of education and that rational belief and critical thinking were epistemically valuable in education solely as a fallible means to true belief. In this case, since Maria's belief is already true, its being also justified - i.e., its being also a fallible means to true belief — couldn't provide the belief with additional epistemic value. ${ }^{8}$ Therefore, in education, justification based on critical thinking must have epistemic value also independently of its instrumental link to truth.

Consider (b). In this case neither Maria's belief nor Mario's is epistemically valuable as a true belief, for they are both false. Nevertheless, it is intuitive that Maria's belief has some epistemic value because - unlike Mario's — it is justified through her critical thinking. Suppose, however, that true belief were the sole ultimate epistemic aim in education and that justified belief and critical thinking were epistemically valuable in education only as a fallible means to true belief. In this case, since Maria's belief is actually false, its being justified via her critical thinking - i.e., its being also a fallible means to true belief — couldn't confer any epistemic value on it. Once again, in education, justified belief based on critical thinking must have epistemic value also independently of its instrumental ties to truth.

We find this case by Siegel in support of epistemic pluralism unconvincing. A problem is that it doesn't show what Siegel would like it to show. Siegel takes conclusion (c) to support the proposition that justified belief resting on critical thinking is a final epistemic aim of education. But (c) only says that, in education, justified belief based on critical thinking must be epistemically valuable also for a reason other than its being a mere means to true belief. The problem is that (c) appears to be compatible with Goldman's epistemic monism. Indeed, advocates of Goldman's 
epistemic monism could reasonably contend that (c) is true because in educational contexts justified belief resting on critical thinking is epistemically valuable also as an indicator of critical thinking, which is in turn only instrumentally epistemically valuable. To defend this claim they could appeal to what Bradley (1998) calls signatory value. According to Bradley, 'something could be good [or valuable] not because of what it causes... but rather because of what it signifies' (1998: 110). ${ }^{9}$ Advocates of Goldman's epistemic monism could contend that Maria's justified belief based on her critical thinking is epistemically valuable also for a reason different from its being a means to true belief. They could claim that Maria's belief is an indicator that Maria is blessed with critical thinking, which is in turn instrumentally epistemically valuable. (That Maria's belief is such an indicator would clearly emerge, for instance, if Maria were asked to justify her belief or defend it from criticism.) Finally, the supporters of Goldman could insist that since critical thinking isn't an ultimate epistemic goal of education but is epistemically valuable as a mere means to true belief, epistemic monism stands unrefuted.

More accurately, philosophers sympathetic to Goldman's views could tell us a story of this sort: in (a), Maria's and Mario's beliefs are both epistemically valuable because they are true. Nevertheless, it is intuitive that Maria's belief has additional epistemic value because it is justified through her critical thinking. In accordance with this, since justified belief resting on critical thinking is epistemically valuable also as an indicator of critical thinking (and not only as a means to truth), Maria's justification actually supplies her belief with additional epistemic value. This is compatible with Goldman's epistemic monism. Furthermore, in (b), neither Maria's belief nor Mario's is epistemically valuable as true belief, for these beliefs are false. Nevertheless, it is intuitive that Maria's belief has some epistemic value because it is justified through her critical thinking. In accordance with this, since justified belief resting on critical thinking is epistemically valuable also as an indicator of critical thinking (and not only as a means to truth), Maria's 
justification actually confers some epistemic value on her belief. Again, this is compatible with Goldman's views.

Siegel contends - in personal communication — that our criticism of his argument is implausible because it relies on a claim dangerously close to the proposition that critical thinking is an indicator of critical thinking, which doesn't appear informative. But our criticism doesn't rely on such an empty claim. We are saying that Maria's having one belief generated and sustained rationally is an indicator of Maria's general ability and inclination to have beliefs generated and sustained rationally. This claim doesn't look uninformative but is quite straightforward. Someone might suggest that in order to ascertain that one of Maria's beliefs is rational, we need previous knowledge that Maria is endowed with critical thinking. If this were correct, our criticism of Siegel's third argument would actually rely on the claim that Maria's critical thinking is an indicator of her critical thinking. But the suggestion cannot be correct. If it were so, it would be impossible to test whether or not a subject is endowed with critical thinking — for example in a school exam — which is clearly false. Our conclusion is that Siegel's third argument doesn't adequately support his epistemic pluralism.

Siegel's fourth argument runs as follows:

Because we lack direct access to truth, we have no choice but to approach truth by way of justification... If so, the basic educational aim should be seen not as the production of true belief, per se, but that of enabling students to judge or estimate wisely the truth... Consequently, critical thinking, and its pursuit of justified belief, are at least as fundamental, educationally, as the aim of true belief. (2005: 352-353)

We don't find this argument very persuasive. Siegel seems to infer from the premise that students have access to truth only via critical thinking and justified belief, where truth is an ultimate epistemic goal of education, the conclusion that critical thinking and justified belief must be another final epistemic aim of education, rather than a mere instrument to get to true belief. We doubt that Siegel's inference is sound. A first concern is that the premise is questionable: one might argue that 
in many cases students simply believe what the teacher tells them on mere trust, without relying on critical thinking. We set this issue aside because we return to it in the penultimate section. Our main worry is that the conclusion of Siegel's argument may not follow from the premise. The inferential principle implicitly used by Siegel seems to say this: if an ultimate aim of a social institution or practice is making $X$ have or be $Y$ (i.e., making students have true beliefs), and the only way to achieve this is making $X$ have or be $Z$ (i.e., making students have critical thinking and justified beliefs), then making $X$ have or be $Z$ is another ultimate aim of the same institution, rather than a mere instrumental aim of it. It is unclear that we should endorse this principle, which we don't find intuitive. ${ }^{10}$ It is easy to find dubious instances of it.

Consider a social institution different from education, say, the fire department (or fire brigade). It is uncontroversial that an ultimate goal of it is extinguishing fire. Take now the following inference that exploits the former principle: a final aim of the fire department is extinguishing fire, and the only ways to do so is removing the oxygen, the fuel, or the heat from it. Therefore, removing oxygen, fuel, or heat from fire is a final aim of the fire department, rather than a mere instrumental aim of it. This conclusion is admittedly odd; some would say false. This casts doubts on Siegel's last case.

\section{DEFENDING SIEGEL'S EPISTEMIC PLURALISM}

Although we have found reasons to conclude that none of Siegel's four arguments in support of his form of epistemic pluralism in education is fully convincing, ${ }^{11}$ nevertheless, we find Siegel's position more intuitively plausible than Goldman's. In the following we outline two additional arguments in defence of Siegel's views, which we find less questionable and more forceful than those examined.

To begin with, Siegel's first and second case do acquire in strength if they are combined and re-framed as one single inference to the best explanation. In other words, the hypothesis that critical 
thinking and rational belief is a final aim of education offers a simple and unified explanation of the impermissibility of certain methods in education (e.g., brainwashing, indoctrination, fabrication and deception) and, simultaneously, of the entrenched practice of teaching truths together with reasons for believing them. Thanks to its simplicity and unifying power, this explanation is more plausible than the mere conjunction of independent explanations of the same phenomena — which must invoke, as we have seen, ethical, epistemic, psychological and practical factors - available to those who embrace Goldman's monism. This provides some support to Siegel's view. ${ }^{12}$

More importantly, we suggest that a variant of Siegel's second thought experiment concerning Maria and Mario does supply another, perhaps stronger, reason to accept Siegel's pluralism. Suppose that Maria and Mario's rational faculties are cognitively disconnected from the world. Imagine that, unbeknownst to them, Maria and Mario have been living in the Matrix, to the effect that the "reality" they have been experiencing is computer-generated. Most of Maria and Mario's beliefs about the world are false, and the relevant belief production processes are unreliable. It is intuitive that these false beliefs would be nevertheless justified if they were supported by Maria and Mario's evidence and — more generally — if they were generated and sustained by Maria and Mario’s critical thinking. ${ }^{13}$

Suppose Maria and Mario take the same exam (in their virtual school) and answer the same question by stating that $P$. Since $P$ aims to describe facts in the world, $P$ is false. Furthermore, imagine that Maria's answer is produced and sustained by her critical thinking, whereas Mario's answer is a mere guess. This scenario is not essentially dissimilar from the one described by Siegel in his second thought experiment. Maria's and Mario's beliefs are still false, and Maria's belief but not Mario's — is still justified as generated and sustained by her critical thinking. The only important difference is that Maria's and Mario's belief production processes are now unreliable, whereas in Siegel's case nothing was specified about this. 
If presented with this scenario, as educators, we should still agree that Maria's belief is epistemically valuable (to some extent at least) and more than Mario's. The intuition would still be that in this educational context Maria's belief has epistemic value because, though false, it is justified through Maria's critical thinking. ${ }^{14}$ How does this support Siegel's epistemic pluralism? Maria's justified belief couldn't have epistemic value as a means to true belief. For none of Maria's belief about the world are such a means in the envisaged scenario. This strongly suggests that fostering rational belief in students through the exercise of their critical thinking is per se an epistemic aim of education. Maria's justified belief is still epistemically valuable also as an indicator of the fact that Maria is endowed with critical thinking. However, in this scenario, Maria's critical thinking couldn’t be epistemically valuable as just a means to true beliefs. For most of Maria's beliefs cannot but be false. Hence, supporters of Goldman's epistemic monism couldn't explain the intuition that Maria's belief is epistemically valuable (more than Mario's) by appealing to that type of epistemic monism.

\section{GOLDMAN AND SIEGEL ON CRITICAL THINKING AND TESTIMONY}

The theme of testimony is central to the philosophy of education (see for instance Bakhurst 2013, Goldberg 2013 and Standish 2019). The dispute between Goldman and Siegel on the epistemic aims of education also touches on this theme. Goldman is convinced that the use and thus the relevance of critical thinking in education is importantly limited because a good portion of teaching consists of teachers making statements without supporting reasons or arguments. This is so because:

Teachers... cannot give reasons for absolutely everything they assert, since reason giving must somewhere come to an end. One cannot defend every premise of every argument with further premises, on pain of infinite regress. (1999: 364)

Goldman claims that it is reasonable for the educational system to expect students to accept at least certain statements on mere trust and without subjecting them to their critical thinking. 
Goldman suggests, however, that an advocate of the critical thinking approach might try to resist his conclusion by maintaining that:

(CT) A hearer is never justified in believing what a speaker (baldly) asserts unless the hearer has good, independent reasons to trust the speaker on that occasion. (1999: 364)

Goldman's main criticism of (CT) turns on his doubts concerning reductionism about testimonial justification, which — according to him — states that:

(RTJ) A hearer is justified in believing speakers' assertions if and only if the hearer has good reasons to trust the speaker, reasons that do not ultimately rest on testimony itself but instead rest wholly on [the hearer's] perception, memory and so forth. (1999: 364)

On (RTJ), a hearer $H$ is (defeasibly) justified in believing a speaker $S$ 's claims just in case $H$ has wholly testimony-free evidence to trust $S$ (cf. 1999: 126). Goldman contends that (CT) is true only if (RTJ) is true (cf. Siegel 2005: 359) and suggests that (RTJ) is false (cf. Goldman 1999: 127).

In his reply, Siegel (2005) concedes that very young pupils don't begin their cognitive lives as critical thinkers, for they must acquire the relevant concepts, skills and abilities. Thus, it is true - but only trivially so - that teachers should expect very young pupils to assent to their claims on mere trust. Yet Siegel contends that (CT) is also true when referred to more mature students, and he launches himself into an example-based defence of (RTJ) applied to education. Siegel argues that grown-up students typically look for and normally find wholly testimony-free reasons to trust their teachers (cf. 2005: 161-163).

Siegel's defence of reductionism about testimonial justification in educational contexts has been dismissed as unconvincing by various authors (cf. Ferreira et al. 2016 and Buckland 2016). Indeed, many epistemologists reject the type of reductionism described by (RTJ) as implausible. A well-known problem is that the hearer in most cases doesn't appear to have sufficient testimony-free 
evidence to support the credibility of the speaker. For what ordinarily passes or may pass for a personal observation of a subject is very often, instead, something that presupposes a host of notions, beliefs and expectations that have been acquired by the subject via testimony (cf. Goldman 1999: 126, see also Coady 1992 and Lackey 2011). For example, Siegel contends that students generally have a variety of wholly testimony-independent reasons to trust their teachers; for instance:

Teachers are in positions of authority; they possess relevant academic credentials; they are treated as experts by their colleagues, administrators, and other adults (including the students' parents); etc. (2005: 361)

However, it is dubious that students could grasp the notions of (epistemic) authority and expert and appreciate their implications for the reliability of a testimonial source, or recognize academic credentials, administrators and colleagues of teachers without resorting to the testimony of other persons at some point of their intellectual development. Indeed, the testimonial process by means of which we acquire notions and beliefs potentially relevant to assessing the reliability of testimonial sources is ubiquitous and endless. Thus, it is questionable that facts like those described by Siegel could actually work as fully testimony-independent reasons of students to trust their teachers. ${ }^{15}$ In general, we think that people's epistemic evaluations can never completely leave the circle of testimony, since language itself has, in a sense, an inherent testimonial nature. This is an important truth that philosophers of education should recognize, but that Siegel (2005) appears to overlook.

We suggest that Siegel could have more chances to succeed if he questioned Goldman's thesis that (CT) entails or presupposes (RTJ). Siegel might try to reject this thesis by arguing along these lines: (CT) states that a hearer $H$ is never justified in believing what a speaker $S$ asserts unless $H$ has good, independent reasons to trust $S$ on that occasion. (CT) doesn't specify, however, that $H$ must have independent non-testimonial reasons. To forestall (trivial) epistemic circularity, 'independent' in (CT) must be interpreted as 'independent of S's testimony'. Yet this doesn't 
prevent $H$ from legitimately using testimonial (or partly testimonial) evidence independent of $S$ 's testimony as a reason for believing what $S$ asserts. For example, student $H$ could be told by teacher $S 2$ that teacher $S 1$ is a reliable source about modern Chinese history. This testimony could then be used by $H$ as a reason to trust $S 1$ as source about modern Chinese history. Cases like these appear quite ordinary and — we submit — they should be accounted for by any satisfactory theory of testimonial justification. So (CT) doesn't entail or presuppose (RTJ).

A concern might be that the regress in $H$ 's search for an ultimate justification for trusting her testimonial sources could turn into an infinite regress. For instance, to trust $S 1$ 's testimony, $H$ might need to rely on $S 2$ 's testimony. Furthermore, to trust $S 2$ 's testimony, $H$ might need to rely on $S 3$ 's testimony. And so on indefinitely. But all this is unnecessary. On a coherentist approach to justification - like the one described in Fricker (1994) ${ }^{16}$ — there is no such infinite regress. As $H^{\prime}$ 's justification would ultimately depend on the web of all her beliefs standing in the appropriate coherence relation.

\section{CONCLUSIONS}

In this paper we have outlined Goldman and Siegel's dispute on the epistemic goals of education. Goldman claims that there is one such goal: true belief. Siegel contends that there are two independent goals: true belief and critical thinking or rational belief. We have argued that Siegel's cases leave themselves open to criticism of various types. Nevertheless, we have suggested two additional arguments that might vindicate Siegel's view. Goldman claims that testimony on mere trust is more fundamental than critical thinking at school. We have also suggested a variant of Siegel's response to Goldman that shields Siegel from the charge of involving a questionable form of reductionism about testimonial justification. 
Correspondence: Dr Luca Moretti, Department of Philosophy, University of Aberdeen, 50-52

College Bounds, Aberdeen AB24 3DS, Scotland, UK

Email: 1.moretti@abdn.ac.uk

\section{ACKNOWLEDGEMENTS}

We are grateful to the audience of the Epistemology of Education Workshop at the University of

Pavia in April 2018, audience of the Annual Philosophy of Education Conference of Great Britain

(PESGB) at the University of Oxford in March 2019, and an anonymous referee of this Journal for

comments on early versions of this article. A special thanks to Harvey Siegel for detailed comments

and criticism on a draft of this paper.

\section{NOTES}

\footnotetext{
${ }^{1}$ Also called weak knowledge by Goldman.

${ }^{2}$ Goldman claims that the actual epistemic value of having a given true belief should always be assessed relative to the interest that we have in it (cf. 1999: 89). A consequence is, for example, that there would be no epistemic value in having a true belief about a subject that we have no interest in (e.g., the exact number of grains of sand on a given beach). Some epistemologists find this notion of epistemic value problematic. For a defence of Goldman see Fallis (2006).

${ }^{3}$ Goldman by 'means' intends 'effective means', where $X$ is an effective means to $Y$ only if the existence of $X$ increases the objective probability of the existence of $Y$, or makes it high.

${ }^{4}$ This thesis is controversial. Goldman (2002) makes cases in favour of it, which are forcefully opposed by Siegel (2005: §4). For general discussion see for instance Bondy (2015) and David (2005).

${ }^{5}$ Suppose a teacher deliberately presents a false proposition $E$ as evidence for $P$. Students would believe that $E$ is true.

${ }^{6}$ Siegel maintains in personal communication that this isn't a faithful reconstruction of his argument. He claims that Siegel (2005) intended to combine what we have identified as his first argument and his second argument into one comprehensive inference to the best explanation similar to the one that we suggest in the next section. We are not sure this is crystal clear in Siegel (2005). If this was Siegel's intention, our suggestion in the next section can be read as a clarifying reconstruction of Siegel's second argument.

${ }^{7}$ Socrates in Plato's Meno notices that a true belief accompanied by a reason to hold it is more stable than a mere true belief, for having a reason why the belief is true helps to keep us from losing it.

${ }^{8}$ This is what Kvanvig (2003) calls the swamping effect of truth.

${ }^{9}$ For example, a physician might say 'that's good', when looking at an X-ray photograph. The physician in this case would see something that is a sign of good health.

${ }^{10}$ In personal communication Siegel denies his commitment to this inferential principle. He claims that his argument simply says that 'in education, judging/estimating the truth is the fundamental value as far as truth is concerned. Whether or not what we take to be true is in fact true is independent of us... [So] from the educational point of view, if our students have judged the truth well, we've succeeded'. We are puzzled by these claims because they seem incoherent with Siegel's epistemic pluralism. Suppose it is true that 'in education, judging/estimating the truth is the fundamental value as far as truth is concerned' and that 'from the educational point of view, if our students have judged the truth well, we've succeeded'. On these assumptions true belief cannot be an ultimate epistemic goal of education. Suppose for instance we happen to live in the Matrix. In these circumstances the epistemic goal of true belief is
} 
unachievable (for what concerns our beliefs about the world). Yet in accordance with Siegel's claims quoted above, education may still succeed in achieving its ultimate epistemic goal(s).

${ }^{11}$ Other scholars find Siegel's arguments wanting; see for instance Buckland (2016).

${ }^{12}$ A reviewer of this Journal notes that this argument to the best explanation may not work for all conceptions of critical thinking available today. We agree. What we are invoking at this point is, specifically, Siegel's conception of critical thinking.

${ }^{13}$ These intuitions harmonize with Siegel's evidentialist conception of justification. Reliabilists like Goldman, on the other hand, are well-known for having difficulties in assenting to them. The basic problem is that if Maria's and Mario's belief formation processes are unreliable, the resulting beliefs should count as unjustified from the reliabilist's point of view, regardless of the evidence the students have (cf. Cohen 1984 and Pollock 1984).

${ }^{14}$ Buckland (2016) contends, against Siegel, that 'a case in which students only ever learned an unending series of false beliefs, but for which they could nonetheless provide excellent rational justifications... [would] not represent the successful attainment of one important and independent epistemic end of education, as per Siegel's account' (106). Our thought experiment suggests that Buckland's contention is mistaken. For Maria can entertain 'an unending series of false beliefs' justified by her critical thinking. But it is intuitive that when these beliefs are compared with Mario's, they do represent 'the successful attainment of one important and independent epistemic end of education'.

${ }^{15}$ Siegel (2005) also emphasizes that 'there is a wealth of indirect, background evidence [based on one's past experience] for accepting as reliable (defeasibly, of course), without direct evidence of its reliability, the testimony of others' (362). However, one might doubt — for the reasons adduced above — that this background evidence is actually testimony-free.

${ }^{16}$ Fricker (1994)'s own position is however unclear. In some passages she seems to endorse a coherentist view of this type, in others she claims that a hearer has a presumptive epistemic right to believe what a speaker asserts even without independent reasons for trusting the speaker.

\section{REFERENCES}

Bakhurst, D. (2013) Learning from Others, Journal of Philosophy of Education, 42, pp. 187-203.

Bondy, P. (2015) Epistemic Value, Internet Encyclopedia of Philosophy. https://www.iep.utm.edu/ep-value/

Bradley, B, (1998) Extrinsic Value, Philosophical Studies, 91, pp. 109-126.

Buckland, L. A. (2016) Social epistemology and the aim(s) of education, South African Journal of Philosophy, 35, pp. 103-110.

Coady, C. A. J. (1992) Testimony: A Philosophical Study (Oxford: Clarendon Press).

Cohen, S. (1984) Justification and Truth, Philosophical Studies, 46, pp. 279-296.

Fantl, G. and M. McGrath (2009), Knowledge in an Uncertain World (Oxford, Oxford University Press).

Fallis, D. (2006) Epistemic Value Theory and Social Epistemology, Episteme, 2, pp. 77-88.

Ferreira, T. A. S., Charbel N. E., and W. J. da Silva-Filho (2016) Knowledge, Belief, and Science

Education, Science and Education, 25, pp. 775-794. 
Fricker, E. (1994) Against Gullibility, in B. K. Matilal and A. Chakrabarti (eds.), Knowing from Words (Boston: Kluwer). pp. 125-161.

Goldberg, S. Epistemic Dependence in Testimonial Belief, in the Classroom and Beyond, Journal of Philosophy of Education, 42, pp. 168-186.

Goldman, A. I. (1992) What is justified belief?, in Goldman, A. I. (ed.), Liaisons: Philosophy meets the cognitive and social sciences (Cambridge, MA, Bradford).

Goldman, A. I. (1999) Knowledge in a social world (Oxford, Clarendon Press).

Goldman, A. I. (2002) The Unity of the Epistemic Virtues, in his Pathways to Knowledge: Public and Private (Oxford, Oxford University Press), pp. 51-70.

Kvanvig, J. L. (2003) The Value of Knowledge and the Pursuit of Understanding (Cambridge, Cambridge University Press).

Lackey, J. (2011) Testimony Acquiring and Knowledge from Others, in A. Goldman and D. Whitcomb (eds.), Social Epistemology: Essential Readings (Oxford, Oxford University Press), pp. 71-91.

David, M. (2005) Truth as the Primary Epistemic Goal: A Working Hypothesis, in M. Steup and E. Sosa (eds.), Contemporary Debates in Philosophy (Oxford, Blackwell), pp. 296-312.

Pollock, J. (1984) Reliability and Justified Belief, Canadian Journal of Philosophy, 14, pp. 103114.

Siegel, H. (1988) Educating Reason: Rationality, Critical Thinking, and Education (New York, Routledge).

Siegel, H. (1997) Rationality Redeemed? Further Dialogues on an Educational Ideal (New York, Routledge).

Siegel, H. (2005) Truth, thinking, testimony and trust: Alvin Goldman on epistemology and education, Philosophy and Phenomenological Research, LXXI, pp. 345-366. 
Siegel, H. (2017) Cultivating Reason, in his Education's Epistemology: Rationality, Diversity, and Critical Thinking (New York, Oxford University Press), pp. 3-19.

Siegel, H. and C. Eamonn (2018) Philosophy of Education, in E. N. Zalta (ed.), Stanford Encyclopedia of Philosophy. https://plato.stanford.edu/archives/win2018/entries/educationphilosophy/.

Standish, P. (2019) Lines of testimony, manuscript.

Watson, L. (2016) The epistemology of education, Philosophy Compass, 11, pp. 146-159.

Williams, E. (2015) In Excess of Epistemology: Siegel, Taylor, Heidegger and the Conditions of Thought. Journal of Philosophy of Education, 49, pp. 142-160. 